\title{
Architecture of GSM based WSN for Greenhouse Monitoring System in Ambient Intelligence Environment
}

\author{
S.Pandikumar \\ Department of Computer Science, Department of Computer Science, \\ Thiagarajar College, India.
}

\author{
S.Ambethkar \\ Dept of Computer Science \& \\ Electronics, Madurai Kamaraj \\ University College, India.
}

\begin{abstract}
Greenhouse monitoring is an essential one for variable climate changes. GSM technologies have been rapidly developing wireless technology during recent years. Starting from telecommunication and industrial controls, it is now being applied in environmental monitoring and agriculture. The old wired greenhouse network would make the measurement system expensive and vulnerable. Moreover, the cabled measurement points are difficult to relocate once they are installed. This paper propose modern greenhouse measurement system using ambient intelligence, the GSM-SMS and sensors are used to sense climate parameters and transmit data through wireless communication.
\end{abstract}

Keywords: Greenhouse, GSM, Wireless Sensor Network, Environmental, Ambient Intelligence, CO2 Emission.

\section{INTRODUCTION}

Ambient intelligence involves the convergence of several computing areas. Simply ambient intelligence is an emerging discipline that brings intelligence to our everyday environments and makes those environments sensitive to us. Ambient intelligence (AmI) research builds upon advances in sensors and sensor networks, pervasive computing, and artificial intelligence, because these contributing fields have experienced tremendous growth in the last few years [1].

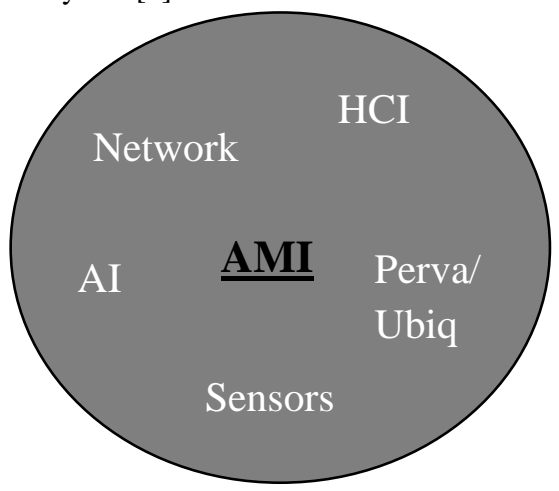

Fig 1: Overview of Ambient Intelligence

Monitoring and computing the greenhouse gases are a major challenging work. Globally, over the past several decades, human-induced activities like industrial revolution and burning of fossil fuels in power stations, vehicle transport systems and industries contribute significantly to the emission and concentration of GHG in atmosphere (www.environment about.com). Avoiding their usage may reduce the emission of GHG, but it may not be a practical approach as they are mandatory in modern day-to-day life, alternatively regular monitoring and reporting of GHG parameters may create awareness to individuals and organization for effective and proper use of human induced activities (http://climate.nasa. gov/key_indicators\#co2). There are very few works done in developing embedded systems for computing GHG [2$11]$.

This paper have implemented a prototype system for sensing and computing the level of existence of GHG parameters (like $\mathrm{CO} 2$, temperature and humidity) in atmosphere using environmental sensors, advanced microcontrollers and energy efficient wireless technologies (figure 2). Data is collected, consistency models are define for analyzing the quality of data and the level of GHG in the deployed environment is computed. The results show that the architecture is capable for monitoring and computation of GHG in the deployed environment and can be applied at all levels of organization for creating awareness, performing scientific studies and to forecast remediation policies by the authorities to individuals and organization in controlling GHG parameters.

In particular, wireless sensor networks (WSNs) uses and implemented in various researches particularly agriculture and environmental because WSN is a flexible and portable. This paper proposes new architecture of greenhouse measurement system using GSM-SMS (Short Message service). A typical standalone greenhouse sensing unit senses the climate parameter such as air temperature, ground humidity, $\mathrm{CO} 2, \mathrm{NO} 2$ etc and transmits to base station through mobile SMS.

\section{BACKGROUND STUDY}

Several authors proposed a novel architecture for greenhouse monitoring through WSN. zhang Qian and Teemu Ahonen et al [5,6] gives the idea about Zigbee based short range WSN for greenhouse monitoring. Orazio Mirabella S.U. Zagade and R.S. Kawitkar et al [7, 8] proposed hybrid architecture (both wired and wireless network) for greenhouse management. In this architecture sensor units sense the climate data in greenhouses and transmit it to control station through wired communication. The wireless section is located in the indoor environment- 

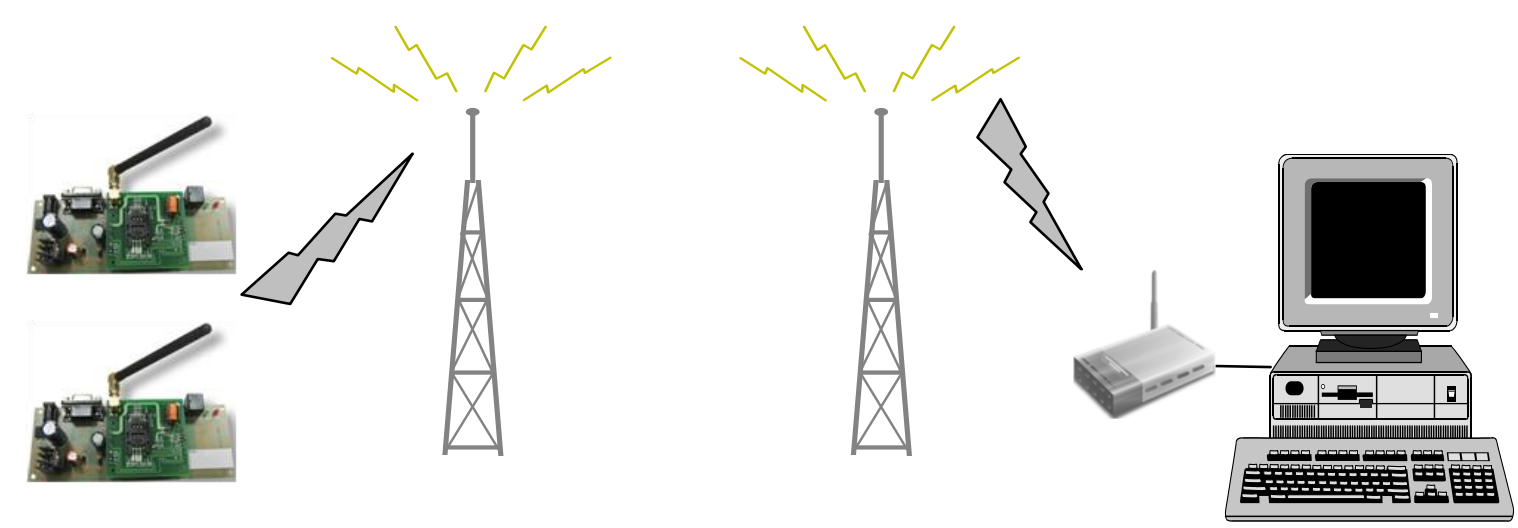

Fig 2: Overview of Greenhouse Monitoring System
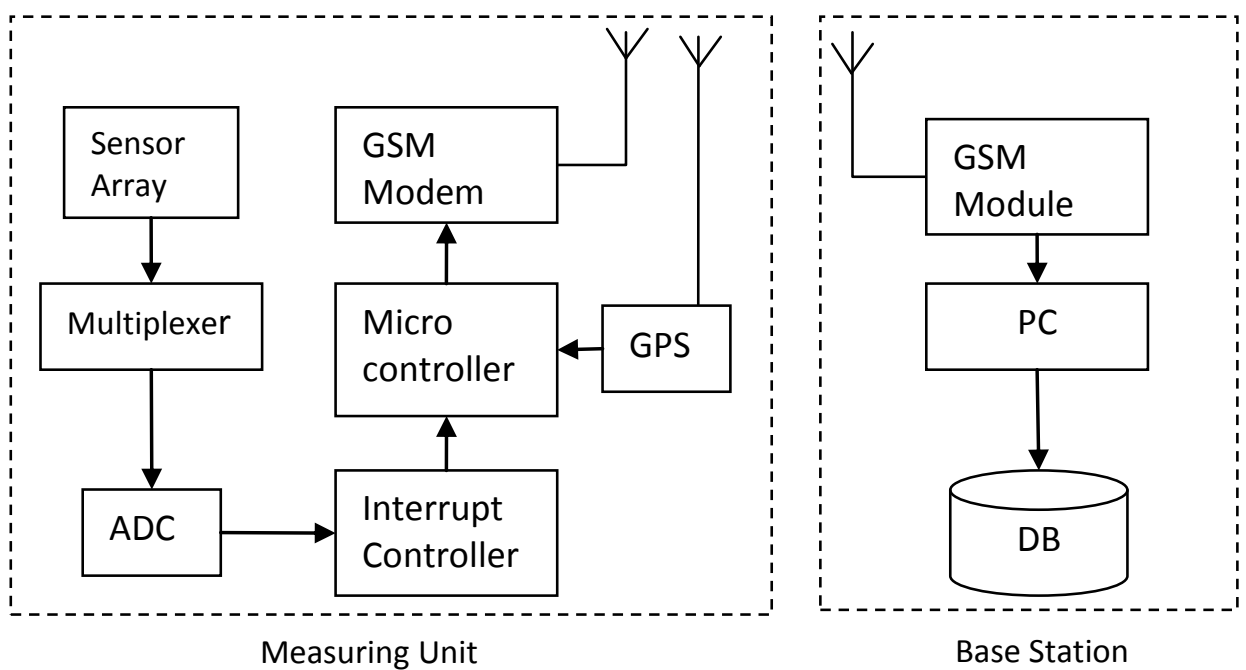

Fig 3: Architecture of Greenhouse Monitoring System

where great flexibility is required, particularly in the production area inside each greenhouse. Andrzej Pawlowski and Mohammad Javad Manashti propose how the greenhouse climate control can be represented as an event-based system in combination with wireless sensor networks [9, 10]. Earl Oliver et al [11] analyze the transport behavior of the SMS and achieve efficient, lowbandwidth, moderate-latency in data communication between mobile devices.

But many of the previous research has been done using Zigbee wi-fi and Bluetooth; these are short range wireless communication technologies so the control ambient is very less. The proposed research uses GSM to cover around the world.

In this paper, the measurement unit sense current $\mathrm{CO} 2$, temperature and humidity level, measure the values and send it to the base station. The mobile SMS can be used to communicate between the centralized server and the measuring unit located to the different parts of the city. The microcontroller reads the climate parameter and constructs special SMS based on predefined structure and sends it to destination.

\section{ARCHITECTURE}

This paper proposes a novel architecture based on GSMSMS. This architecture has two major parts that is measuring unit and base station. Here the GSM wireless technology is used to data transfer in a secured channel from measuring unit to base station. The measurement unit has gas, temperature and humidity sensors, GPS receiver and GSM modem (figure 3). The prototype model has four input channel and ADC. The ADC has $4 \times 1$ multiplexer that's converts sensors analog value into digital data. The microcontroller reads GHG parameters and location coordination then construct green SMS and it will send to base station

\subsection{Sensors}

A Sensor is a device that detects or measures a real-world condition, such as motion, heat or light and converts it to an equivalent analog or digital representation [19]. In this paper we have used $\mathrm{CO} 2$, temperature and humidity semiconductor sensors. A gas sensor detects particular gas molecules and produces an electrical signal whose magnitude is proportional to the concentration of the gas. This paper uses K-33 ELG 1\% CO2/Temp/RH Data 
Logging Sensor is to detect $\mathrm{CO} 2$ concentration in the proto- type model.

\subsection{GPS Receiver}

The GPS module provides the physical coordinate location of the Measurement unit, time and date. It continuously transmits serial data (RS232 protocol) in the form of sentences according to NMEA (National Marine Electronics Association) standards (www.nmea.org). The latitude and longitude values of the location are contained in the GPGGA sentence (refer NMEA format). In this architecture, these values are extracted from the GPGGA sentence and construct SMS by microcontroller.

\subsection{Data Processing of $\boldsymbol{\mu c}$}

Microcontroller $(\mu \mathrm{c})$ is the brain of this architecture because its control the entire component in the measurement unit directly. The $\mu \mathrm{c}$ reads co2 value location coordinates and time then construct the special structured SMS and send it through GSM network. The $\mu \mathrm{c}$ uses AT (Attention) commands to access GSM modem [18]. In this proposed architecture the $\mu \mathrm{c}$ can support 4 sensors, one GPS and one GSM components. The $\mu \mathrm{c}$ create interface with GPS and GSM components through RS232 protocol.

\section{BASE STATION}

The base station contains GSM module, monitoring software and centralized database. The GSM module used to receive a data from measuring unit in the form of mobile SMS. The monitoring software run in server computer which is reads SMS from GSM module, parse the data and stored in database.

\subsection{The Monitoring System}

The MS (Monitoring System) continuously monitors GSM module for incoming SMS. The special SMS has unique structure which is constructed by microcontroller of embedded unit. Once the NEW_MESSAGE event generated by GSM module the MS reads newly arrived SMS and check it whether special SMS or not. If it so, it parse and extract the data. The special SMSs are always start and end with special symbol like '\#','@,', \&', etc. and this paper uses '\#' symbol. After confirming special SMS, the MS parsing data based on <SPACE > and <ENTER> whitespaces. For example the incoming SMS like "\#ID AA001 <enter>POS 9.58N,78.10E<enter >CO2 365 <enter> TEMP $30<$ enter>HUM $24<$ enter>TIME 13:00\#” In this example MS checks starting character and then parse SMS into actual parameters like

$\begin{array}{ll}\text { ID } & : \text { AA001 } \\ \text { POSITION } & : \text { LAT:9.58N, LAN:78.10E } \\ \text { CO2 } & : 365 \text { PPM } \\ \text { TEMP } & : 30 \mathrm{C} \\ \text { HUMIDITY } & : 24 \\ \text { TIME } & : 13: 00\end{array}$

This parsed data will be stored into database for future use.

\subsection{GSM Interface}

The GSM receiving module acts as a gateway in this architecture. This receiving module can be a GSM/GPRS modem, mobile phone or any SMS send/receiving device. This device connects with computer and microcontroller through USB or serial cable [16]. The AT (Attention) commands are used to managing connections and send/receive the SMS. Sample AT Commands are "AT+CMGL" List messages, "AT+CMGR" Read message, "AT+CMGS" Send message [16]. The interface module communicates with GSM device and reads the SMS and checks whether it's a command SMS or ordinary SMS. If it's a command SMS, this commands are executed by the local computer.

\section{EXPERIMENTAL WORK}

The prototype model is tested in central point of Madurai city and receives the measurement at every half an hour. The sensing unit fit at 5 feet top from the ground level and ensures the GSM coverage is in moderate level. The distance between the sensing unit and base station is around $10 \mathrm{Km}$.

\subsection{Measurement of $\mathrm{CO} 2$ Concentration}

The prototype model measures $\mathrm{CO} 2$, temperature and humidity value at frequent intervals. In December 2012 the average $\mathrm{CO} 2$ concentration in Madurai city is 379.5 sixteen hours receiving data is given below.

Table 1. Average Greenhouse parameters

\begin{tabular}{|c|c|c|c|}
\hline Parameter & $\begin{array}{l}\text { Average } \\
\text { Value }\end{array}$ & $\begin{array}{l}\text { Minimum } \\
\text { Value }\end{array}$ & $\begin{array}{l}\text { Maximum } \\
\text { Value }\end{array}$ \\
\hline Co2 & 379.5 & 370 & 389 \\
\hline Temperature & 29 & 26 & 32 \\
\hline Humidity & 58 & 48 & 68 \\
\hline
\end{tabular}

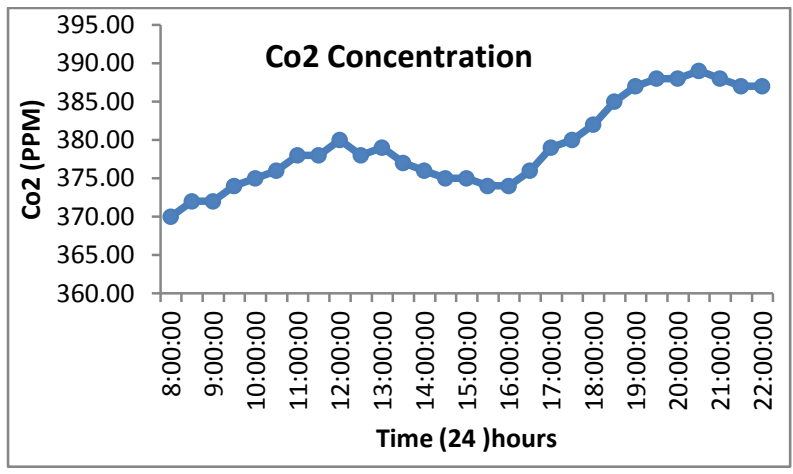

Fig: 4. Co2 concentrations

\subsection{Measurement of Temperature}

Due to high $\mathrm{CO} 2$ concentration the average temperature in Madurai city is $29^{\prime} \mathrm{C}$ and average humidity is 58 . The figure 5 shows various levels of temperature and humidity from GMT 8:30 to 15:00. 


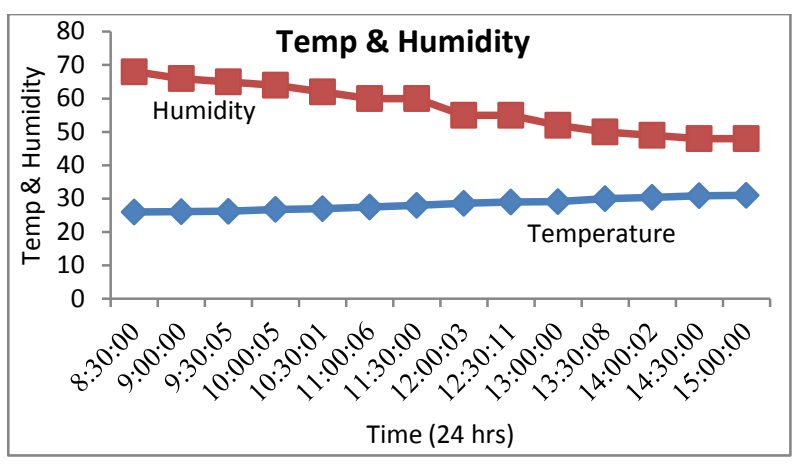

Fig: 5. Temperature and Humidity level

\subsection{Measurement of SMS Arrival Rate}

In GSM architecture SMS messages are carried on either SD-CCH or SACCH [13] depending on the use of the traffic channel. When the TCH (Traffic Channels) is not allocated, i.e., no voice call or data transfer in progress, the short message is carried on the SDCCH (stand alone dedicated control channel). In this architecture the GSM module does not commit TCH but it's dedicate to Sending SMS only so it's always use SDCCH to send SMS. Basically the SMS delivery is based on network, location and time $[12,13]$.

Let $\lambda s m s, \lambda l$ and $\lambda v$ be the arrival rates for SMS message, Location updation and voice call setup respectively. the arrival rate of this aggregate traffic that uses SDCCH channels is given by $\lambda c=\lambda s m s+\lambda \imath+\lambda v$.

Let the mean service time (i.e. channel holding time) for a single SMS message be $\mu_{s m s}^{-1}$, and that of location updation and voice call setup message be $\mu_{l}^{-1}$ and $\mu_{v}^{-1}$ for respectively. The unconditional expected service time of an arriving message is then given by

$$
\mu_{c}^{-1}=\frac{\lambda_{s m s}}{\lambda_{c}} \times \mu^{-1}+\frac{\lambda_{l}}{\lambda_{c}} \times \mu_{l}^{-1}+\frac{\lambda_{v}}{\lambda_{c}} \times \mu_{v}^{-1}
$$

Figure 6 shows the variations of SMS delivery time between $8 \mathrm{AM}$ to 10PM. Here the lowest delivery time of green SMS is one second at 2:10PM and the highest delivery time is 6 seconds at 7:50PM. The average delivery time of this architecture is 3.5 seconds and zero data lose.

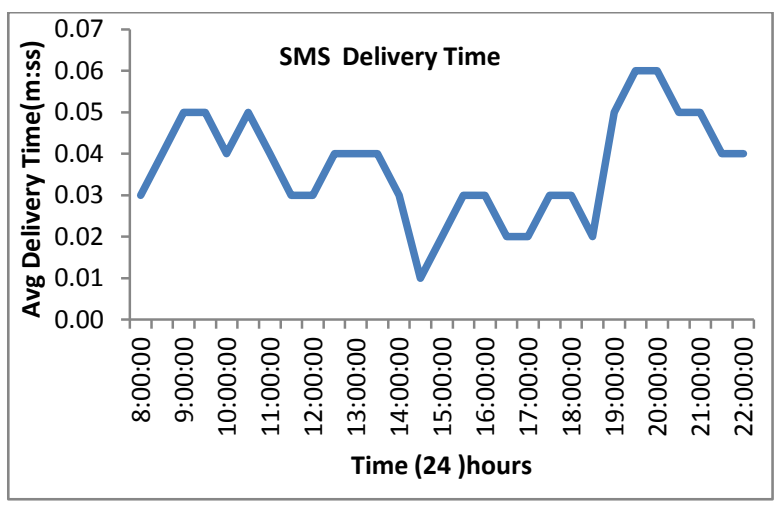

Fig: 6. SMS Delivery Delay Time

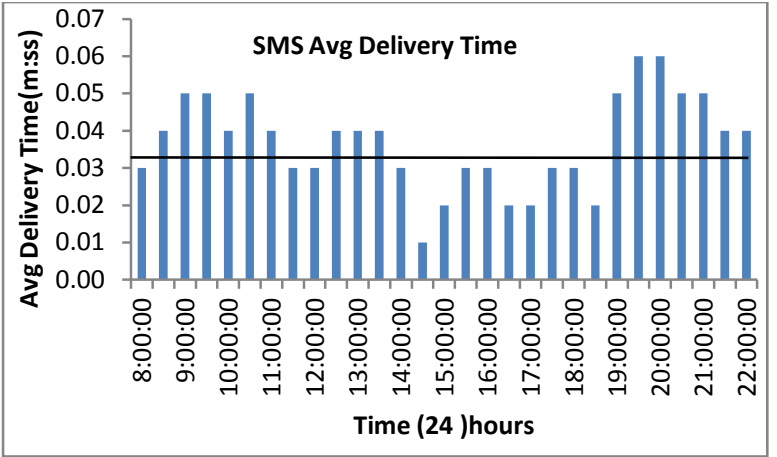

Fig: 7. Average SMS Delay Time

\section{CONCLUSION}

This paper presents an embedded system design of wireless sensor monitoring system for sensing and computation of environmental parameters. A $\mathrm{Co} 2$ commercial sensor had been integrated with ARM processor to monitor and compute the level of existence of GHG parameters (like $\mathrm{CO} 2$, temperature and humidity) in atmosphere using information and communication technologies. Prototype operates for data gathering and data transmission using GSM-SMS and preliminary test prove that the developed prototype is capable to monitor and compute $\mathrm{CO} 2$, temperature and humidity parameters in the deployed environment and has several advantages in term of fast delivery, zero data lose, low cost, flexibility, user friendliness and energy efficiency. The established GSM network is a highly efficient and the average SMS deliver time is $3.5 \mathrm{sec}$. This greenhouse monitoring system will create awareness, performing scientific studies and to forecast re mediation policies by the authorities to individuals and organization in controlling global warming and GHG parameters.

In future this architecture will extend to allocate new channel in GSM architecture for green data transmission, there after the environmental data will transmit with specialized GSM channel for low traffic and high performance.

\section{REFERENCES}

[1] Juan Carlos Augusto, 2010. "Ambient Intelligence: Basic Concepts and Applications", Technical Document, University of Ulster, Jordanstown, UK.

[2] Y. Zhou, X. Yang, X. Guo, M. Zhou, and L. Wang, "A design of green-house monitoring \& control system based on ZigBee wireless sensor network," inProc. Int. Conf. WiCom, Sep. 21-25, 2007, pp. 2563-2567.

[3] L. Gonda and C. E. Cugnasca, "A proposal of greenhouse control using wireless sensor networks," inProc. 4th World Congr. Conf. Comput.Agric. Nat. Resour., Orlando, FL, Jul. 24-26, 2006.

[4] B. van Tuijl, E. van Os, and E. van Henten, "Wireless sensor networks: State of the art and future perspective," inProc. Int. Symp. High Technol. 
Greenhouse Syst. Manage. (Greensys), 2007, pp. $547-554$.

[5] zhang Qian, yang Xiang-long, zhou Yi-ming, WANG Li-ren, guo xi-shan, 2007. "A wireless solution for greenhouse monitoring and control system based on ZigBee technology", Journal of Zhejiang University science A.

[6] Ahonen, T. 2008. "Greenhouse Monitoring with Wireless Sensor Network", Mechtronic and Embedded Systems and Applications, MESA 2008. IEEE/ASME International Conference, Beijing, pp $403-408$.

[7] Orazio Mirabella and Michele Brischetto, 2011. "A Hybrid Wired/Wireless Networking Infrastructure for Greenhouse Management", IEEE transactions on instrumentation and measurement, vol. 60 , no. 2 , pp 398-407.

[8] S.U. Zagade, R.S. Kawitkar, 2012. "Wireless Sensor Network for Greenhouse", International Journal of Science and Technology, Volume 2 No.3, March. Pp 130-133.

[9] Andrzej Pawlowski, Jose Luis Guzman, Francisco Rodríguez, Manuel Berenguel, José Sánchez and Sebastián Dormido, 2009. "Simulation of Greenhouse Climate Monitoring and Control with Wireless Sensor Network and Event-Based Control", Sensors,pp 232252.

[10] Mohammad Javad Manashti, Houshang Ghamarnia, Soheila Amirian, Ramin Mohammad Nezhad, 2012. "Design GSM-SMS based system for old structured greenhouses with monitoring and logging network sensors", International Research Journal of Applied and BasicSciences. Vol., 3 (7), 1497-1507.

[11] Earl Oliver, 2011. "Characterizing the Transport Behaviour of the Short Message Service", MobiSys'10, June 15-18, San Francisco.

[12] "GSM Technical Specification", ETSI Technical Document, GSM 04.11 Version 5.1.0. March 1996.

[13] Nilesh Agarwal, Leena Chandran-Wadia and Varsha Apte, 2010. "Capacity Analysis of the GSM Short Message Service" Technical Document, Indian Institute of Technology Bombay.

[14] Zohar Naor, 2004. "An efficient short messages transmissionin cellular networks". In Proceedings of INFOCOM, pages 640-649.
[15] Shahin Charkhandeh, M.G. Petovello, R. Watson and G. Lachapelle, 2006. "Implementation and Testing of a Real Time Software-Based GPSReceiver forx86 Processors", The Institute of Navigation National Technical Meeting (ION NTM 2006) January, pp. 1820

[16] S.Pandikumar, 2012. "A Model for GSM Based Intelligence PC Monitoring System", International Journal of Advanced Computer Science and Technology, Volume 2, Number 2 (2012), pp. 85-88.

[17] N. Kularatna, and B. H. Sudantha, 2008. "An environmental air pollution monitoring system based on the IEEE 1451 standard for low cost requirements," IEEE Sensors Journal, 8, (4), pp. 415 -422 .

[18] Anuj Kumar, I. P. Singh, and S. K. Sud, 2009 "Indoor Air Quality Estimation by Using Smart Sensing System", Proceedings of the International MultiConference of Engineers and Computer Scientists, Vol II, March 18 - 20, Hong Kong.

[19] Luo, H.Q., Zhang, X., Liu, E., Qiao, X.J., Zhang, Y.H., 2006. The design of wireless sensor in greenhouse environment measurement. Sensor World, 12(5):45-48

[20] Earl Oliver, 2010. "Characterizing the Transport Behaviour of the Short Message Service", MobiSys'10, June 15-18, San Francisco.

[21] Hesong Huang, Hongning Bian and Shuchuan Zhu, 2011. "A Greenhouse Remote Monitoring System Based on GSM", International Conference on Information Management, Innovation Management and Industrial Engineering, Vol 2, pp 357-360.

[22] J. C. Augusto, 2007. Ambient intelligence: the confluence of ubiquitous/pervasive computing and artificial intelligence. Intelligent Computing Everywhere, pages 213-234. Springer London.

[23] Juan Carlos Augusto, 2010. "Past, Present and Future of Ambient Intelligence and Smart Environments", Agents and Artificial Intelligence. Vol 67, pp 3-15.

[24] J. Fraden, 2004. "In: Handbook of Modern Sensors," Third Eds., Springer.

[25] G. Peersman, S. Cvetkovic, P. Griffiths, and H. Spear, 2000. "The global sys-tem for mobile communications short message service," IEEE Personal Communications. 